\title{
USO DE VIDEOAULAS COMO RECURSO DIDÁTICO: Critérios de Análise e Seleção
}

\author{
Luciano Dias da Silva ${ }^{1}$ \\ Maurício Capobianco Lopes²
}

\begin{abstract}
RESUMO
Este artigo apresenta parte do resultado de uma pesquisa (SILVA, 2017a) cujo objetivo é analisar o uso de videoaulas como recurso didático utilizando a sala de aula invertida em aulas de Físico-Química. Trata-se de uma pesquisa qualitativa, cujos instrumentos utilizados para a geração dos dados foram videoaulas disponíveis na Internet, diário de campo com as observações sobre o seu uso por um grupo de estudantes e um questionário de avaliação das videoaulas aplicado a este mesmo grupo de estudantes. A análise das videoaulas foi feita com base em critérios de qualidade para a produção de vídeos e nas impressões dos estudantes. Como resultados destacam-se a criação de um produto educacional contendo uma playlist com vídeos gravados pelos pesquisadores e outras com as melhores videoaulas utilizadas durante a execução do projeto, de modo a facilitar a organização dos estudos de cada aluno, como também a pesquisa dos professores que não tenham tempo de fazer sua própria seleção de videoaulas. O uso de videoaulas foi aprovado por mais de $90 \%$ dos alunos que participaram da pesquisa, todos estudantes de cursos técnicos integrados ao Ensino Médio. Conclui-se que o uso de videoaulas pode ser um importante recurso para os professores, aproximando o ensino de Físico-Química de um modelo que atende de forma mais efetiva os estudantes que utilizam as tecnologias e, em especial, a linguagem dos vídeos em seu dia a dia.
\end{abstract}

Palavras-chave: tecnologias digitais na educação; videoaula; ensino de química; ensino de físico-química; Youtube.

\section{USE OF VIDEO-LECTURES AS A DIDATIC RESOURCE: ANALYSIS AND SELECTION CRITERIA}

\section{ABSTRACT}

This article presents a piece of a research (SILVA, 2017a) whose objective is to analyze the use of video-lectures as a didactic resource using flipped classroom in Physics-Chemistry classes. It is a qualitative research, whose data generate instruments used were video-lectures available on the internet, a field diary about their use by a group of students, and an assessment questionnaire applied to the same group of students. The analysis of the vide-lectures was made based on quality criteria to produce videos and on the students' impressions. As results, we highlight the creation of an educational product containing a playlist with videos recorded by the researchers and others with the best video-lectures used during the execution of the project, in order to facilitate the organization of students studies student as well to teachers who do not have time to make your own video-lectures selection. The use of video classes was approved by more than $90 \%$ of the students who participated in the research, all them studying in technical high school courses. It is concluded that the use of video-lectures can be an important resource for teachers, bringing Physical Chemistry teaching closer to a model that more effectively serves students who use technologies and, in particular, the language of videos used in their day by day.

Keywords: digital technologies in education; video-lecture; chemistry teaching; physics-chemistry teaching; Youtube.

Recebido em: 2/3/2020

Aceito em: 20/4/2020

\footnotetext{
${ }_{1}$ Autor correspondente. Instituto Federal de Santa Catarina, IFSC - Campus Criciúma. Rodovia SC-443, 845 - Vila Rica. Criciúma/SC, Brasil. CEP 88813-600. http://lattes.cnpq.br/8173901079316492. https://orcid.org/0000-0002-0448-4861. luciano.silva@ifsc.edu.br

2 Fundação Universidade Regional de Blumenau. Blumenau/SC, Brasil. http://lattes.cnpq.br/2487859882670844. https://orcid.org/00000003-0796-0293.
} 


\section{INTRODUÇÃO}

O modelo atual de ensino predominante nas escolas brasileiras já foi muito eficaz, mas está saturado, pois a sociedade mudou muito, em especial na forma de produzir e disseminar o conhecimento. Funcionava quando não existia a Internet e havia pouco acesso ao conhecimento e aos materiais (TREVELIN; PEREIRA; OLIVEIRA NETO, 2013), mas, como deixam claro os sucessivos resultados do Brasil no Pisa - Programa Internacional de Avaliação de Estudantes (BARBA, 2016; PAIVA, 2016), não funciona mais.

Os jovens de hoje são muito diferentes dos de gerações anteriores e não se trata apenas de mudanças de valores, muitas vezes causadoras de "conflito de gerações", que são diferenças naturais resultantes das mudanças de costumes e da evolução (?) da sociedade: são mudanças mais profundas. Veen e Vrakking (2009) chamam os jovens atuais de "homo zappiens", enquanto Prenski (2001) denomina-os de "nativos digitais", pois interagem desde muito jovens com as tecnologias digitais e têm de lidar com um conjunto cada vez maior de informações, diferentemente dos estudantes do passado. Prensky (2001) ainda destaca que:

Essas diferenças são muito maiores e mais profundas do que a maioria dos educadores imaginam ou percebem. [...] É muito provável que os cérebros dos nossos alunos tenham mudado fisicamente - e que sejam diferentes dos nossos - como resultado de como eles cresceram. Mas se isto pode ser literalmente verdade ou não, podemos dizer, com certeza, que seus padrões de pensamento mudaram ( $p$. 1 , tradução nossa).

O fato aparentemente inconteste é que o ensino tradicional, que atendeu de forma satisfatória às gerações anteriores, já não consegue do mesmo modo "atender às necessidades dos estudantes, que pensam, processam e aprendem de maneira completamente diferente da geração que os antecede, devido à inserção das Tecnologias da Informação e Comunicação (TICS) em suas vidas cotidianas, desde a mais tenra infância" (KRIPKA; VIALI; LAHM, 2016, p. 54).

Muitas formas de ensinar hoje não se justificam mais. Perdemos tempo demais, aprendemos muito pouco, desmotivamo-nos continuamente. Tanto professores como alunos temos a clara sensação de que muitas aulas convencionais estão ultrapassadas (MORAN, 2004, p. 11).

Não deve causar espanto esse descompasso entre o que a escola oferece e exige dos alunos e a realidade por eles vivida. Sibilia $(2012$, p. 13) define a escola como "um intrincado artefato destinado a produzir algo" e não vê dificuldade em verificar que essa aparelhagem está incompatível com as crianças de hoje. "A escola seria, então, uma máquina antiquada" (2012, p. 13). Silva e Camargo (2015) destacam que, historicamente, a cultura escolar tem se caracterizado por certo atraso em relação às transformações surgidas nas concepções de vida cultural, tanto no Brasil quanto no mundo todo.

Além das diferenças entre as gerações recentes e as anteriores, contudo, sabe-se que, mesmo dentro de uma mesma geração e de um mesmo grupo social, as pessoas são díspares e aprendem de forma diversa. Logo, não é muito eficaz dar o mesmo tratamento ou ensinar a todos da mesma forma. Como, porém, personalizar o ensino quando um professor tem de atender 30, 40 alunos ao mesmo tempo dentro de uma sala de 
aula? Para Lima e Moura (2015), personalizar não implica preparar um planejamento para cada aluno, mas disponibilizar todas as ferramentas possíveis para garantir que eles aprendam. "Se um aluno aprende com um vídeo, outro pode aprender mais com uma leitura, e um terceiro com a resolução de um problema - e de forma mais completa, com todos esses recursos combinados" (LIMA; MOURA, 2015, p. 98). Tal compreensão induz à ideia de que personalizar o ensino é, na verdade, criar situações que facilitem a personalização da aprendizagem.

Huberman (1992) afirma que, durante sua vida profissional, um professor passa por várias etapas ou fases, no que ele chama de "ciclo de vida profissional dos professores". Segundo este autor, na fase chamada por ele de diversificação, os professores

lançam-se, então, numa pequena série de experiências pessoais, diversificando o material didático, os modos de avaliação, a forma de agrupar os alunos, as seqüências do programa, etc. (...) Implicitamente, a busca de novos desafios responderia a um receio emergente de cair na rotina (HUBERMAN, 1992, p. 41-42).

Uma dessas alternativas que tem se popularizado desde o advento da Internet é o uso de videoaulas. Dias, Esposito Junior e Demarque (2013) destacam como vantagem o maior controle do aluno sobre a exposição, pois pode pausar, retroceder ou rever a videoaula. Hirdes et al. (2006) também destacam a possibilidade de o aluno assisti-la quando e onde estiver mais propenso ao estudo e não no horário e local previamente marcados para a aula.

Existem muitas videoaulas disponíveis gratuitamente na Internet, de forma que o professor pode escolher as que melhor se adéquam às suas turmas: só precisa ter clareza sobre os critérios de avaliação para a seleção. As dicas de alguns autores para os professores que pretendem gravar suas videoaulas também podem servir como critério de seleção. A seguir apresentamos algumas destas sugestões: ser breve e falar com entusiasmo (BERGMANN; SAMS, 2016), usar linguagem clara e objetiva (KHAN, 2013), ater-se a um único tópico principal (DASH, 2002), enfatizar as principais ideias com base na entonação e utilizar a expressão corporal na comunicação (CARRAVETA, 2015). Se preferir, o professor pode gravar suas próprias videoaulas, para o que deve, além de considerar as citadas propostas, conhecer as possibilidades existentes tanto em termos técnicos quanto financeiros: desde a utilização de uma webcam ou um aplicativo de captura de tela com sobreposição de voz até a gravação em um estúdio profissional (FRANCISCO et al., 2015).

As videoaulas podem ser usadas tanto como complemento para aulas tradicionais como em salas de aula invertidas. Para usar com seus alunos, o professor pode preferir videoaulas de professores que tenham um estilo semelhante ao seu, para facilitar a adaptação de seus alunos, ou buscar videoaulas de professores com estilos diferentes, para atingir aqueles estudantes que têm dificuldade com o seu estilo. Talvez esta seja uma opção mais interessante quando a ideia é utilizá-la como complemento à aula presencial tradicional, enquanto aquela parece ser mais adequada à sala de aula invertida.

Assim, este trabalho propôs-se a analisar videoaulas como recurso didático utilizando a sala de aula invertida em aulas de Físico-Química. Foram identificadas videoaulas na Internet sobre o tema e, após uma análise baseada em critérios objetivos, dispo- 
nibilizou-se uma pré-seleção de videoaulas de Físico-Química organizada em playlists de cada conteúdo, a saber: Soluções, Termoquímica, Cinética Química, Equilíbrio Químico e Eletroquímica. Em seguida, foi colhida a impressão dos estudantes sobre as mesmas. A partir disso, foi criado um produto educacional com um conjunto de videoaulas para o ensino de Físico-Química, de modo a facilitar a organização dos estudos de cada aluno, como também a pesquisa dos professores que não tenham tempo de fazer sua própria seleção de videoaulas. Também parte do produto educacional, foi elaborado um guia de aplicação com dicas e sugestões baseadas nas pesquisas realizadas e na experiência proporcionada pela execução do projeto. São apresentados critérios claros e objetivos para a seleção de videoaulas, respeitando as particularidades de cada área do conhecimento. Pretende-se, assim, auxiliar de maneira objetiva professores que queiram usar videoaulas com seus alunos e/ou adotar a sala de aula invertida.

\section{REVISÃO DE LITERATURA}

O termo vídeo ("eu vejo", em Latim) pode fazer referência a dois conceitos: vídeo como tecnologia, que diz respeito ao avanço tecnológico e a sua popularização, e vídeo como linguagem audiovisual, que se refere à forma como podemos utilizar essa tecnologia (HIRDES et al., 2006). Esta última é a que nos interessa neste trabalho. Para Lisbôa, Bottentuit Junior e Coutinho (2009), o vídeo não pode ser considerado somente um recurso de apoio às aulas, mas, antes de tudo, um meio de comunicação. Dessa forma, ele deve fazer parte de uma estratégia de ensino e aprendizagem que proporcione aos alunos uma variedade de atividades. Em entrevista ao Portal do Professor, José Manuel Moran (2009) destacou algumas características do uso pedagógico de vídeos, entre as quais: facilitam a motivação e o interesse por novos assuntos; são mais dinâmicos em razão da possibilidade de contar história, mostrar imagens e possibilitar dramatizações; oferecem apoio sensorial para além da linguagem meramente textual, apoiando-se fortemente no recurso visual e auditivo; adaptam-se a todo processo de ensino e aprendizagem; têm maior potencial de despertar a curiosidade e o interesse.

Moran (1994) destaca algumas situações em que o uso de vídeos é particularmente recomendável: "a compreensão do que não temos presente fisicamente, mas simula a presença do que está longe (um vídeo sobre a Sibéria), do que fisicamente poderia ser difícil executar (um vídeo sobre uma reação química que provocasse uma explosão)" (p. 42).

Hirdes et al. (2006) destacam, entretanto, que "desde o início da inserção do vídeo até hoje, muito pouco se investiu na qualificação dos professores para um melhor aproveitamento do potencial didático educativo desse recurso em sala de aula" (p.6).

Uma das formas de uso pedagógico de vídeo que mais tem se popularizado são as videoaulas. De acordo com Zanata, Caramano e Marques (2016), videoaula pode ser definida como aula em formato audiovisual. Esse formato traz diversos benefícios a quem estuda por seu intermédio. Hirdes et al. (2006) destacam a melhor concentração possibilitada pelo uso de vídeos, afinal o aluno poderá escolher quando assisti-los, no momento em que se sentir mais predisposto ao estudo, além da possibilidade de aprofundar o estudo quando julgar conveniente "pois em qualquer momento pode parar o vídeo e fazer uma pesquisa sobre o assunto" (HIRDES et al., 2006, p. 2). 
Um dos pontos fortes do uso das videoaulas como recursos pedagógicos, tanto em salas de aula invertidas como em salas de aulas tradicionais, é o fato que nas videoaulas o aluno tem um maior controle sobre a exposição. $O$ aluno pode usar recursos de pausar, retroceder e avançar e até mesmo rever a videoaula, enquanto que em uma exposição presencial isso não acontece (DIAS; ESPOSITO JUNIOR; DEMARQUE, 2013, p. 6).

Vialli et al. (2011) apresentam como vantagem do uso de videoaulas de qualidade o discurso direto e objetivo, sem interrupções ou brincadeiras comuns em uma aula presencial, seja por parte do professor, para prender a atenção dos alunos, ou destes mesmos, com conversas paralelas, além da possibilidade de ser acessada de qualquer parte do mundo, usando um computador conectado à Internet. Por outro lado, a necessidade de acesso à rede mundial pode se configurar num problema, uma vez que nem todos têm acesso à Internet banda larga. A maior limitação apresentada por estes mesmos autores, entretanto, é a falta de interatividade entre professor e aluno: quando existe uma dúvida sobre o conteúdo, o aluno só pode voltar o vídeo e vê-lo novamente, sem a possibilidade de intervenção (VIALLI et al., 2011).

Embora sua popularização seja relativamente recente, sobretudo graças à Internet, o uso de videoaulas não é exatamente uma novidade. Nos anos 80, na Universidade do Vale do Rio dos Sinos (Unisinos), microaulas eram gravadas em vídeo para treinamento e capacitação de futuros professores, nas disciplinas de Prática de Ensino (CARRAVETA, 2015).

Um dos expoentes da recente popularização das videoaulas é Salman Khan. Em 2004, depois de ajudar uma prima com dificuldades em Matemática que morava a cerca de 2.500 quilômetros de distância, Khan começou a gravar alguns vídeos com aulas de Matemática e postá-los no YouTube. A ideia deu tão certo que em 2009 pediu demissão para se dedicar integralmente àquilo que se transformou na Khan Academy. Além dos vídeos, Khan montou um software para criar exercícios (KHAN, 2013). As videoaulas da Khan Academy são apresentadas em torno de 10 minutos com linguagem clara e objetiva (CARRAVETA, 2015).

Na primavera de 2007 Aaron Sams e Jonathan Bergmann, professores de Química de uma escola de Ensino Médio em uma região relativamente rural no Colorado, Estados Unidos, começaram a gravar vídeos a partir de slides em PowerPoint com inclusão de voz e anotações e disponibilizar essas videoaulas on-line para os seus alunos. A princípio, o objetivo era ajudar os alunos que faltavam muito por causa de esportes ou outras atividades e evitar ter de repetir as explicações e, com isso, otimizar o tempo das aulas, mas mesmo os alunos que compareciam normalmente às aulas começaram a assistir os vídeos, especialmente ao estudar para as provas. Com os vídeos postados on-line, passaram a ser acessados por alunos e professores de todo o mundo (BERGMANN; SAMS, 2016).

Atualmente, muitas videoaulas são disponibilizadas na Internet, grande parte podendo ser acessada gratuitamente. Boa parte delas mantém o modelo do ensino presencial com o professor explicando na frente de uma lousa e utilizando alguns recursos como desenhos e ilustrações, ou então com sua voz em off e animações e exercícios na tela do computador ou de um tablet (CARRAVETA, 2015). Mais recentemente, têm-se 
tornado comuns videoaulas mais produzidas, com fundo em chroma-key e interação do professor com elementos gráficos elaborados na pré-produção. A partir de 2009 o YouTube criou um link, o YouTube EDU, que reúne material das mais variadas áreas, permitindo acesso facilitado e gratuito a diversas videoaulas, que podem ser usadas em ensino presencial ou a distância (CARRAVETA, 2015).

Para Vialli et al. (2011), o recurso da videoaula tem se difundido muito devido à sua facilidade e eficiência.

É possível, de forma dinâmica, gravar o discurso e a imagem do professor e, assim, reproduzir toda a estratégia didática que o docente aplica em sua aula. Como por exemplo as expressões faciais e corporais, entonação da voz, gestos. Também é muito comum incluir nos vídeos, informações gráficas: mapas, gráficos, esquemas, desenhos, sons e outros (p. 3).

Caso deseje usar videoaulas com seus alunos, o professor pode pesquisar entre as diversas opções disponíveis na Internet aquelas que considere mais adequadas. Para isso, o primeiro passo é assisti-las por inteiro. Verificar se não há erros conceituais graves e se a aula apresentada é agradável a quem assiste - se não agradar ao professor, um profissional da disciplina, dificilmente agradará aos alunos. O professor da videoaula deve mostrar conhecimento e segurança, deve falar com entusiasmo de forma a cativar quem se dispõe a assistir (BERGMANN; SAMS, 2016). Caso não encontre videoaulas que considere adequadas ou prefira gravar suas próprias videoaulas, existem algumas opções:

$\mathrm{Na}$ construção de elementos multimídia como videoaulas, diversas técnicas e recursos poderão ser utilizados. Dentre eles, destacam-se os estúdios de gravação, com todos seus custos (tempo, pessoal e dinheiro) associados. Pode-se gravar ainda com handcams, webcams e/ou celulares, com um custo baixo. Contudo, esses recursos podem comprometer a qualidade do material. Por fim, pode-se usar ferramentas para a geração de vídeos no formato de animação, a partir de um áudio pré-gravado e de personagens pré-definidos pelos proponentes (FRANCISCO et al., 2015, p. 78).

De toda forma, a videoaula deve seguir o conceito de microconteúdo apresentado por Anil Dash: "informação publicada de forma resumida, com sua extensão ditada pela restrição de um único tópico principal e pelas limitações físicas e técnicas do software e dispositivos que usamos para visualizar conteúdo digital" (DASH, 2002, p. 1, tradução e grifo nossos). Tal cuidado ajuda o aluno a manter o foco e a atenção, pois videoaulas muito longas e sem um objetivo claro tendem a facilitar a dispersão.

Bergmann e Sams usam o lema "um tópico é igual a um vídeo" (2016, p. 40) e procuram manter-se sempre abaixo de 10 minutos. Essa ideia vai ao encontro do que propõe Valente (2014) ao afirmar que "é preciso dosar o número de vídeos e o tamanho dos vídeos. A ideia não é substituir a aula presencial por vídeos, pois os alunos reclamam do fato de a aula expositiva ser 'chata' e essa mesma aula transformada em vídeo pode ficar mais chata ainda!" (p. 90). Conhecer os cuidados necessários à produção de uma videoaula é interessante não apenas a quem pretende gravá-la e produzi-la, mas também a quem pretende utilizar videoaulas prontas, pois ajuda a escolher entre as opções disponíveis na Internet. 
Uma possibilidade de criação de vídeos caseiros apontada por Vialli et al. (2011) é realizada por meio de softwares de gravação de telas e sons produzidos pelo usuário de computador, que lhe permitem criar um vídeo a partir da gravação de todos os movimentos feitos no computador combinado à sua narração. Silveira et al. (2019) apresentam uma opção ainda mais simples: usar um conhecido programa, o Microsoft PowerPoint, que permite gravar a apresentação de slides, inclusive com a possibilidade de captar a imagem da webcam no canto da tela, para que o aluno possa ver o rosto do professor durante a explicação. "Este recurso permite criar videoaulas de qualquer aplicativo usado no computador, e, com a facilidade de compartilhamento desses vídeos na Internet, uma grande quantidade de conhecimento passou a ser distribuída na grande rede" (VIALLI et al., 2011, p. 1-2).

Para tornar a videoaula mais interessante a um público mais exigente, no entanto, ela deve ser concebida por uma equipe especializada e multidisciplinar. Vialli et al. (2011) chamam-na de "videoaula profissional". Para este tipo de videoaula, Medina e Bacelar (2016) chamam a atenção para a necessidade da roteirização, um trabalho conjunto do professor, o especialista no conteúdo e do designer de conteúdo, profissional de comunicação responsável pela estruturação didática das cenas e pela sugestão de elementos audiovisuais enriquecedores, como animação, ilustrações e sons, que deve atuar no nível mais técnico do roteiro, definindo enquadramento de planos e movimentação de câmeras (MEDINA; BACELAR, 2016).

Martins, Barreto e Borges (2009) chamam a atenção para o fato de que "o desconhecimento das possibilidades estético-pedagógicas do recurso audiovisual pode representar um significativo obstáculo para as oportunidades pedagógicas possibilitadas pelo uso deste recurso" (p. 13). Estes autores afirmam que o

diálogo entre o diretor técnico-artístico e o professor se mostra imprescindível para o desenvolvimento da videoaula, inserindo-se num processo pedagógico importante, possibilitando trocas ricas, não apenas para uma melhor apresentação do conteúdo temático preparado pelo professor, mas também para incorporar com qualidade técnica e pedagógica as possibilidades ampliadas pela utilização do meio audiovisual (recursos da linguagem, estímulo à participação do interagente, etc.) (MARTINS; BARRETO; BORGES, 2009, p. 13).

Carraveta (2015) considera o microensino, uma técnica apresentada por Flávia Sant'Anna (1979), adequada por permitir "organizar o contexto, formular perguntas, variar a situação de estímulo, conduzir ao fechamento, ilustrar com exemplos, utilizar reforços e facilitar a comunicação" (CARRAVETA, 2015, p. 51). Igualmente, para essa mesma autora, "o professor deve sentir-se à vontade, como se estivesse numa aula presencial. Trata-se de um professor e de uma videoaula e não de uma apresentação para TV ou interpretação de ator" (p. 59). Lembrando que o professor é um comunicador, Carraveta (2015) afirma que a videoaula será tão mais eficiente quanto melhor for a habilidade de comunicação do professor:

Como o professor vai dar a aula para uma câmera, sem o retorno imediato da reação dos alunos, ele precisa eleger esta habilidade como prioritária. [...] Destacam-se as seguintes formas de comunicação: Comunicação oral: clara, concisa, coerente, com vocabulário preciso e encadeamento de ideias. Entonação: enfatizar ideias 
principais, através da entonação com exclamações, interrogações, reticências, vírgulas e pontos. Pausas e silêncios: permitir que os alunos pensem através de pequenos momentos de interrupção da comunicação oral. Expressão corporal: utilizar o corpo, expressões corporais, faciais, gestuais na comunicação de mensagens. Ganchos de atenção: intercalar conteúdo com recursos, estabelecendo ganchos de atenção (p. 53).

Medina e Bacelar (2016) relatam um projeto cuja proposta era estabelecer um único formato para a elaboração de videoaulas, aplicável para qualquer área de conhecimento, mas chegaram à conclusão de que isso não é possível, pois existem peculiaridades e necessidades que se aplicam às diferentes áreas (humanas, exatas, biológicas). Os estudantes convidados a participar da pesquisa demonstram declaradamente uma preferência pelo formato jornalístico de videoaula, cuja forma de apresentar o conteúdo deixa a informação mais clara e facilita o entendimento e a concretização do conhecimento abstrato, enquanto a videoaula clássica tornou-se maçante e deixou os alunos bem mais cansados durante a sua audiência. Nota-se que a explicação do professor não foi, ao menos nesse caso, considerada pelos alunos o melhor método.

Isso nos leva a refletir sobre o papel do professor no processo educativo. [...] Aqui, entende-se que a presença do docente no processo de ensino-aprendizagem é fundamental, no entanto é inegável a alteração do seu papel. [...] Neste sentido, o professor não será suprido pelo jornalista ou roteirista, mas sim incorporado à equipe (MEDINA; BACELAR, 2016, p. 105).

Entendemos que o conhecimento das possibilidades, bem como das dificuldades encontradas em cada opção, auxiliará os professores na decisão de gravar suas próprias videoaulas - e que tipo de produção será escolhida neste caso - ou usar videoaulas já disponíveis na Internet. Os critérios a serem observados na seleção das videoaulas não diferem muito dos cuidados a serem tomados na sua gravação: deve-se verificar se tais cuidados foram tomados por quem as gravou. Para isso, como destacam Aranha et al. (2019, p. 23), o professor deve assistir os vídeos "com calma, identificando todos os itens que podem ser explorados".

\section{PROCEDIMENTOS METODOLÓGICOS}

Aqui são apresentados os procedimentos metodológicos utilizados no percurso da pesquisa, com os procedimentos tomados desde a pesquisa bibliográfica, os instrumentos utilizados na geração de dados e as metodologias utilizadas na análise destes dados.

\section{Revisão Bibliográfica}

A revisão bibliográfica começou por meio do site de buscas Google Acadêmico (scholar.google.com.br). Este site tem uma ferramenta bastante interessante, que são os alertas: é possível cadastrar palavras-chave e ser avisado por e-mail quando algum trabalho científico é publicado com elas. Também foram feitas consultas à Biblioteca Digital Brasileira de Teses e Dissertações (bdtd.ibict.br/vufind/), ao Banco de Teses e Dissertações da Capes (bancodeteses.capes.gov.br) e ao Portal de Periódicos da Capes (periodicos.capes.gov.br). 
A partir do resultado das buscas pelas palavras-chave escolhidas, procedeu-se à seleção dos trabalhos considerados pertinentes, descartando-se aqueles que não interessavam. A primeira análise foi feita a partir do título dos textos. Os resumos dos trabalhos pré-selecionados foram, então, lidos e avaliados. Somente os artigos e dissertações cujos resumos foram considerados relevantes foram lidos na íntegra. As obras citadas nesses trabalhos - livros, artigos, teses e dissertações - consideradas relevantes também foram lidas na íntegra.

\section{Campo de Estudo}

O campo de estudo da pesquisa foi o local onde o professor-pesquisador já trabaIhava. Para a aplicação da metodologia proposta foram escolhidas três turmas de cursos técnicos integrados ao Ensino Médio, nas quais o aluno cursa tanto as disciplinas da área técnica quanto as da formação geral na mesma instituição.

A aplicação da metodologia ocorreu em dois momentos distintos. No segundo semestre de 2015 (2015-2) a metodologia foi aplicada na disciplina "Físico-Química II" com a $4^{\text {a }}$ fase do curso técnico em Química, turma de 27 alunos (dois alunos com 18 anos, dois com 17 e os demais com 16 anos), com a qual o professor-pesquisador já tinha contato e bom relacionamento por ter ministrado disciplinas em todas as fases anteriores do curso, inclusive "Físico-Química I" na fase imediatamente anterior. Essa turma será identificada pela sigla "Q5".

No semestre seguinte (2016-1) a metodologia foi aplicada novamente na disciplina "Físico-Química II" com a 4a fase do curso técnico em Química, turma de 20 alunos (à exceção de uma aluna com 19 anos, metade com 16 anos e outra metade com 17), e na disciplina "Físico-Química" com a $3^{\text {a }}$ fase do curso Técnico em Informática, turma de 15 alunos (três alunos com 15 anos, dois com 17 e os demais com 16 anos). Essas turmas serão identificadas neste trabalho pelas siglas "Q4" e "I3", respectivamente.

A disciplina "Físico-Química II" é ministrada na 4a fase do Curso Técnico em Química Integrado ao Ensino Médio e tem duas aulas semanais, com aproximadamente $25 \%$ de sua carga horária constituída de aulas experimentais (em laboratório), organizadas e ministradas por outro professor, com a colaboração do professor titular da disciplina. Os módulos de conteúdos previstos para esta disciplina são: cinética química; equilíbrio químico e iônico e eletroquímica.

A turma 13, diferentemente das outras, não é do curso de Química, por isso o nível de aprofundamento nos conceitos estudados é menor do que naquelas em que a Química é considerada uma disciplina técnica: aqui ela é tratada como uma disciplina de "formação geral". Isso fica claro na carga horária das disciplinas: enquanto no curso de Química a Físico-Química é vista em dois semestres consecutivos, na $3^{\mathrm{a}}$ e na $4^{\mathrm{a}}$ fase, no curso de Informática toda a Físico-Química é vista em um único semestre, em três aulas semanais. Os módulos de conteúdos previstos para esta disciplina são: dispersões e soluções; propriedades coligativas; termoquímica; cinética química; equilíbrio químico e iônico e eletroquímica. 


\section{Geração de Dados}

O processo de seleção das videoaulas na Internet começou com a busca "videoaula de [o conteúdo a ser ministrado]" no site de hospedagem de vídeos YouTube. Devido à formação inicial do professor, Licenciatura em Química, e por serem estes os conteúdos previstos para as turmas nas quais a metodologia foi aplicada, todas as videoaulas eram de diversos conteúdos de Físico-Química: soluções, propriedades coligativas, termoquímica, cinética química, equilíbrio químico, equilíbrio iônico, oxirredução e eletroquímica.

As anotações periódicas do professor-pesquisador eram baseadas nas suas observações pessoais e no feedback constante dos alunos ao longo dos semestres, fosse em momentos dedicados a isso ou em conversas informais dos estudantes com o professor. Um questionário de avaliação foi aplicado aos alunos para descobrir qual era a sua concepção prévia sobre videoaulas e o que havia se modificado após essa experiência.

\section{Análise dos Dados}

A bibliografia referente às videoaulas ajudou a definir seus critérios de análise e seleção, o que deveria ocorrer necessariamente antes da sua utilização com os alunos. A partir da observação do professor-pesquisador e do feedback dos alunos, associados às respostas destes a um questionário, surgiram novos elementos para reavaliação das videoaulas usadas. Com base nesses dados foram criadas playlists com algumas das videoaulas usadas.

Para a análise dos dados a criação de categorias é, segundo Franco (2008), ponto crucial. O Quadro 1 apresenta, de forma esquemática, o objetivo da pesquisa, as categorias de análise, os instrumentos de geração de dados e os autores que embasaram a análise. As categorias de análise foram definidas a priori.

\section{Quadro 1 - Matriz para a Análise e Interpretação dos Resultados}

\section{Objetivo:}

Definir critérios de análise e seleção de videoaulas.

Categorias de análise:

- Correção conceitual.

- Organização e coerência na apresentação dos conteúdos.

- Desenvoltura e clareza do professor na apresentação.

- Foco e tempo de duração da videoaula.

- Percepção da qualidade da videoaula por parte dos alunos.

Referências utilizadas na análise dos dados:

- Bergmann e Sams (2016), Carraveta (2015), Dash (2002) e Vialli et al. (2011).

Instrumento de coleta/geração de dados:

- Site de hospedagem de vídeos YouTube

- Anotações do professor-pesquisador

- Questionário de avaliação. 
As videoaulas foram avaliadas pelo professor-pesquisador a partir de critérios de qualidade encontrados na literatura pesquisada e baseado em sua própria experiência docente. A opinião dos alunos após a disponibilização também foi considerada na avaliação das videoaulas.

\section{ANÁLISE DOS DADOS}

Nesta seção são apresentados os resultados das análises das videoaulas e das respostas dos alunos à parte do questionário apresentado a eles ao final da pesquisa.

\section{Análise das Videoaulas}

A partir dos critérios citados anteriormente (não ter nenhum erro conceitual grave, apresentação clara e organizada, tempo total reduzido e foco definido) foram selecionadas as videoaulas disponibilizadas aos alunos. Embora não haja números exatos, para cada videoaula escolhida foram assistidas pelo menos cinco outras videoaulas que não agradaram. A maioria das videoaulas escolhidas foi dos mesmos professores e dos mesmos canais do YouTube, mostrando certa coerência, pois é esperado que os cuidados de um professor ao gravar suas aulas sejam tomados por ele em todas as suas videoaulas. Em alguns casos foram disponibilizados aos alunos mais de uma opção de cada conteúdo, sendo considerada muito importante, em especial nesses casos, a opinião deles, o que acabou por estabelecer um novo filtro para as turmas seguintes.

Para tratar de "Soluções", apenas uma videoaula foi selecionada, do professor Ruffini, do canal "Aulalivre.net". Nesta videoaula o professor apresenta-se ao lado de uma TV (usada como monitor) e vai passando os slides de uma apresentação e explicando os conteúdos, com clareza e correção, característica defendida por Carraveta (2015). As videoaulas desse professor, no entanto, são mais longas que o desejável - esta tem cerca de 22 minutos - por tratar de todo um capítulo e não de um tópico específico, contrariando o que defendem Dash (2002) e Bergmann e Sams (2016), o que as torna mais adequadas para revisão. 0 maior problema das aulas desse professor, porém, é o ritmo de sua fala, muito lenta, longe de transmitir o entusiasmo defendido por Bergmann e Sams (2016): foi esta a característica mais criticada também pelos alunos. Ao menos isso pôde ser corrigido ajustando a velocidade nas configurações do vídeo $(x 1,5)$.

A melhor videoaula encontrada para "Propriedades Coligativas" foi do professor Carvalho, do canal "Tenho Prova Amanhã" que, além de ser um professor desenvolto, utiliza elementos gráficos bastante úteis inseridos na edição, características elogiadas por Vialli et al. (2011). Essa videoaula tem uma duração bem menor (cerca de 10 minutos), mas ainda trata de dois tópicos que poderiam ser apresentados em dois vídeos em sequência, o que não chegou a comprometer a qualidade: a videoaula foi elogiada pelos alunos. Para uma propriedade coligativa não apresentada nessa videoaula (osmoscopia), foi sugerida a parte final de outra videoaula do professor Ruffini, do canal "Aulalivre.net". Como a sugestão foi assistir somente os seis minutos finais, não se verificou o problema da falta de foco nem do tempo excessivo da videoaula, mas o ritmo da fala do professor permanecia o mesmo. 
Também do professor Ruffini foi a videoaula indicada para os conceitos básicos da "Termoquímica". A clareza e a coerência na organização e apresentação dos conceitos, em nossa avaliação, compensam os problemas já citados das suas videoaulas. Para aprender as formas de se calcular a variação da entalpia de uma reação, foram indicadas duas videoaulas do professor Artur Ramos, do canal "Kinapse Vestibulares", além de uma videoaula do canal "o kuadro", usada apenas para um exemplo de aplicação da Lei de Hess. Nesta videoaula não aparecia o rosto do professor, apenas sua voz em off e as imagens capturadas de um tablet. Manter o foco (a resolução de um único exercício) e falar com clareza são as maiores virtudes dessa videoaula, cujo professor não foi identificado.

As videoaulas do professor Artur Ramos apresentam o seu rosto enquanto explica os conceitos alternando a tela com a apresentação de slides com superposição da voz dele. Aqui, além da correção conceitual, da clareza e da coerência na organização e apresentação dos conceitos, já se percebia um entusiasmo do professor, tal como apregoado por Bergmann e Sams (2016), e a delimitação de um tópico por vídeo, também defendido por estes autores e por Dash (2002). Uma única restrição foi feita por alguns alunos, que se incomodaram com a imagem muito fechada no professor, que poderia ficar mais afastado da câmera.

Para introduzir os conceitos básicos da "Cinética Química", foram sugeridas três opções: uma videoaula do professor Igor, do canal "Stoody", uma do professor Paulo Valim, do canal "Química em Ação", e outra do professor Artur Ramos, do canal "Kinapse Vestibulares". Para os fatores que interferem na velocidade de uma reação química, foram indicadas duas opções: duas aulas sequenciais do professor Artur Ramos, do canal "Kinapse Vestibulares" ou uma do professor Paulo Valim, do canal "Química em Ação". Para a Lei de Ação das Massas inverteu-se: foram indicadas duas aulas sequenciais do professor Paulo Valim, do canal "Química em Ação", ou uma do professor Artur Ramos, do canal "Kinapse Vestibulares". A videoaula mais elogiada foi a do professor Igor, do canal "Stoody", que apresenta um formato bem tradicional, com giz e quadro, mas com um professor bastante desenvolto e seguro. O tempo de duração é um pouco maior que o desejável (cerca de 15 minutos) e os tópicos abordados permitiriam dividi-la em duas ou três videoaulas, mas a julgar pela reação dos alunos, a qualidade da explicação compensa. É o perfeito exemplo de que os critérios de avaliação das videoaulas não devem ser excludentes. Talvez o maior problema desse canal seja o fato de que ele oferece gratuitamente apenas a primeira videoaula de cada módulo, cobrando pela sequência do conteúdo.

As videoaulas do professor Artur Ramos, do canal "Kinapse Vestibulares" repetem as características já citadas anteriormente. Já as videoaulas professor Paulo Valim, do canal "Química em Ação", foram consideradas muito cansativas. Nestas não aparecia o rosto do professor, apenas sua voz em off e as imagens capturadas de um tablet, mas o que mais incomodou foi a falta de entusiasmo percebido na voz do professor ("chegou a dar sono", segundo alguns alunos). Para revisão de Cinética, foi sugerida uma videoaula do professor Ruffini, do canal "Aulalivre.net". Como já referido, o fato de as videoaulas desse professor tratarem de todo um capítulo e não de um tópico específico as tornam mais adequadas para revisão do que para a introdução de um conteúdo novo. 
"Equilíbrio Químico" foi apresentado por meio de três videoaulas do professor Artur Ramos, do canal "Kinapse Vestibulares": a primeira sobre os Conceitos Básicos do Equilíbrio Químico, a segunda sobre "Constante de Equilíbrio" e a terceira sobre "Deslocamento de Equilíbrio", todas com as mesmas características já citadas para as videoaulas desse professor. Sobre "Equilíbrio lônico" foi utilizada uma videoaula, do professor Carlos Vitorino, do canal "Descomplica", que apresenta um formato tradicional, com giz e quadro. O professor não mostra tanta segurança quanto o professor Igor (que usa o mesmo formato), mas o resultado final é satisfatório. Um diferencial dessa videoaula é que em determinado momento foi dado um zoom no quadro, com o professor fora da imagem, como que simulando a captura da imagem de um tablet ou slides de PowerPoint, entretanto, por não se aprofundar tanto quanto desejado, foi necessária a complementação do conteúdo com exposição presencial.

Nas turmas em que foi necessária uma revisão de "Oxirredução", assunto de Química Geral que já fora estudado em fases anteriores, foram disponibilizadas duas videoaulas, uma do professor Paulo Valim, do canal "Química em Ação" e outra do professor Igor, este agora em outro canal do YouTube, "Hexag Medicina", mas mantendo o estilo e a qualidade de suas aulas. Já a videoaula do professor Paulo Valim foi muito mais elogiada que as de Termoquímica deste mesmo professor: nesta ele se apresenta diante do quadro-negro e com giz, mas percebeu-se muito mais empolgação (às vezes excessiva).

As videoaulas de "Eletroquímica" foram: pilhas, do professor Igor, canal "Stoody", cálculo do potencial de uma pilha e corrosão, do professor Paulo Valim, canal "Química em Ação", novamente com a voz sem entusiasmo em off e as imagens capturadas de um tablet, e eletrólise do professor Ruffini, do canal "Aulalivre.net", na verdade a parte final de uma videoaula em que ele apresenta toda a Eletroquímica.

Ao cruzar os critérios técnicos definidos pelos autores que embasaram essa análise com as avaliações feitas pelos alunos, algumas observações são necessárias. Nas videoaulas mais elogiadas, as do professor Igor, este se apresentou com "os bons e velhos quadro e giz", enquanto as videoaulas mais criticadas, do professor Paulo Valim, foi utilizada a captura de um tablet e da voz do professor em off e as videoaulas desse mesmo professor em que ele se apresentou com giz e quadro foram mais elogiadas. Isso quer dizer que nossos alunos preferem as videoaulas que mais se assemelham a uma aula tradicional? Não necessariamente, pois as aulas do professor Artur Ramos, que também usa captura de tela com voz do professor em off e não usa giz e quadro, foram elogiadas. O que se percebe é que a segurança, a clareza e o entusiasmo com que o professor explica são mais importantes para o aluno que os recursos técnicos utilizados, o que vai ao encontro do que afirmam Bergmann e Sams (2016).

\section{Análise do Questionário}

A análise das respostas ao questionário mostra que, dos 58 alunos que o responderam, apenas 8 nunca tinham assistido videoaulas (Figura 1a). A maioria (31) já o fazia por hábito, dos quais a maior parte (23) apenas em conteúdos nos quais tivessem dificuldade. Parcela considerável (19 alunos) afirmou já ter assistido videoaulas, mas não tinham o hábito. 
No espaço do questionário reservado para comentários, um dos alunos explicou o motivo de gostar de videoaulas:

[Eu já tinha o hábito de estudar por videoaulas] pois tenho muita dificuldade em prestar atenção na aula, então com o vídeo eu fico voltando até entender, e na aula não faço isso para não atrapalhar o andamento da aula.

Tal explicação vai ao encontro do que dizem Dias, Esposito Junior e Demarque (2013), quando afirmam que uma das maiores vantagens da videoaula é que "o aluno pode usar recursos de pausar, retroceder e avançar e até mesmo rever a videoaula, enquanto que em uma exposição presencial isso não acontece" (2013, p. 6).

Nenhum dos 50 alunos que já haviam estudado por videoaulas considerou essas experiências negativas, no entanto apenas 22 alunos aprovaram sem restrições: a maior parte ( 28 alunos) fez ressalvas por haver encontrado aulas boas, mas também haviam perdido tempo com aulas ruins (Figura 1b). Talvez por isso apenas 5 alunos tenham afirmado não achar interessante ter videoaulas indicadas ou referendadas pelo professor (Figura 1c).

Figura 1 - Respostas dos alunos a parte do questionário

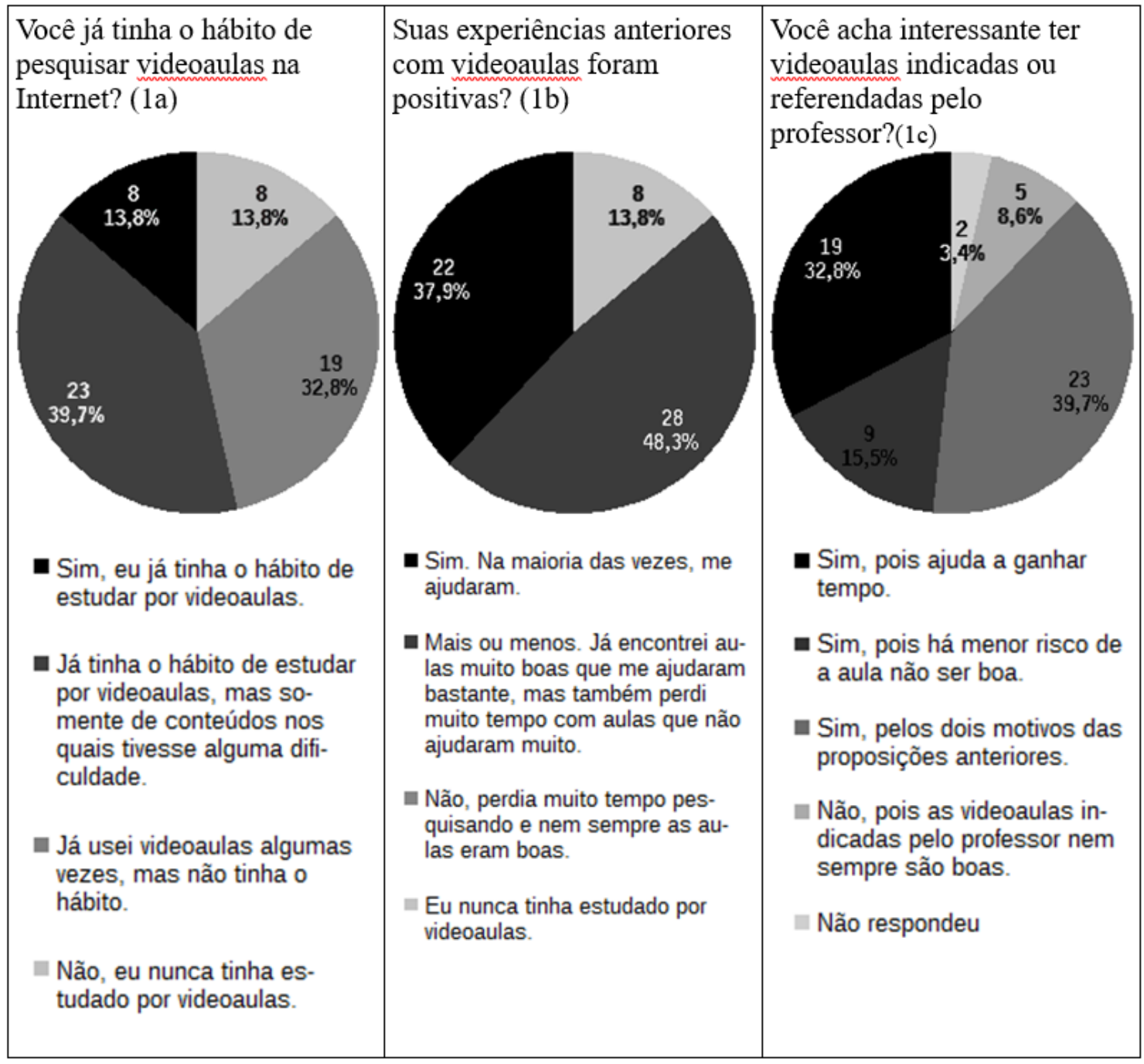

Fonte: Dados da pesquisa. 
Para 32 alunos a indicação do professor reduz as chances de a aula não ser boa e 42 acham que essa indicação ajuda a ganhar tempo. Um aluno chegou a afirmar, num comentário, que considera a indicação do professor condição para o uso de videoaulas:

Acredito que o método de videoaula só é válido se os vídeos forem indicados pelo professor, caso contrário poderá confundir o aluno, além de ficar refém de um conteúdo equivocado e superficial.

Corroborando esse ponto de vista, outro aluno da turma que nunca havia estudado por videoaulas explicou o motivo:

Eu nunca pesquisei por videoaulas pois achava que poderia ter informações erradas ou algum conteúdo que não tivesse sido explicado em aula, o que me confundiria.

Essas opiniões reforçam a importância da escola e do professor no ensino, mesmo em seus formatos inovadores. O professor não perde sua importância, muda apenas 0 seu papel (MEDINA; BACELAR, 2016). Além de ajudar o aluno a interpretar e contextualizar os conceitos estudados (MORAN, 2004), tem o importante papel de, no caso específico do uso de videoaulas, gravá-las ou selecionar as que considerar adequadas aos seus alunos entre as que encontrar na Internet (EDUCAUSE, 2012), como fez o professor-pesquisador e como passou a fazer o coordenador do curso - que também é professor de Química - com suas turmas após acompanhar o desenvolvimento desta pesquisa. Também cabe ao professor, dependendo da proposta metológica adotada, validar as videoaulas sugeridas pelos alunos.

Outro aluno sugeriu a criação de um canal no YouTube:

Eu acredito que se você quiser usar isso mesmo em suas aulas, seria bom fazer um canal com todos os vídeos separados em assuntos (playlist), na ordem dos semestres, assim tendo acessibilidade para o aluno.

O professor achou muito boa essa sugestão: criar uma playlist com todos os vídeos a serem usados durante o semestre para auxiliar na gestão do próprio tempo por parte do aluno. A organização das videoaulas em playlists pode ser útil tanto aos alunos quanto aos professores que pretendem utilizá-las.

\section{CONSIDERAÇÕES FINAIS}

O objetivo geral desta pesquisa foi analisar o uso de videoaulas como recurso didático utilizando a sala de aula invertida. Limitando a presente análise ao escopo deste artigo, buscou-se conhecer critérios de qualidade para seleção e/ou gravação de videoaulas. Pretendia-se, assim, auxiliar de maneira objetiva professores que queiram usar videoaulas com seus alunos.

Como produto educacional, foi criada no YouTube uma playlist com vídeos que apresentam e discutem os principais conceitos trabalhados nesta pesquisa, um dos quais (SILVA, 2017b) apresenta dicas e/ou sugestões para gravação e seleção de videoaulas, além de playlists com as melhores videoaulas utilizadas durante a execução do projeto, cuja criação visa a facilitar a organização dos estudos de cada aluno e a pesquisa dos professores que não tenham tempo de fazer sua própria seleção de videoaulas. 
A escolha do formato de vídeo para o produto educacional deveu-se principalmente à facilidade de polinização permitida pela grande popularidade do YouTube, de forma a contribuir com a qualidade do ensino do maior número possível de alunos.

Ao procurar "definir critérios de análise e seleção de videoaulas", a pesquisa revelou que muitos critérios de qualidade das videoaulas são compartilhados por vários autores, alguns deles - como Dash (2002), Valente (2014) e Vialli et al. (2011) - partindo de referenciais teóricos, e outros - como Khan (2013) e Bergmann e Sams (2016) - a partir de suas próprias experiências. A experiência prévia do primeiro autor do presente trabalho, com gravação e uso de videoaulas, também contribuiu para a definição de critérios. Não ter erros conceituais é o mínimo necessário para uma boa videoaula. Também é importante um professor desenvolto, que apresenta e explica o conteúdo de forma clara e organizada e que transmite segurança aos alunos que assistem suas aulas. Aulas de curta duração e com foco definido também tendem a ter melhores resultados.

Por fim, a opinião dos alunos também é importante: caso eles não gostem de alguma videoaula, é importante entender os motivos disso e usá-los como critérios para uma busca mais personalizada. Oferecer mais de um vídeo para um mesmo assunto também pode ser, em um primeiro momento, uma boa opção. É necessário, contudo, tempo, paciência e disposição para assistir várias videoaulas até encontrar algumas que possam ser consideradas satisfatórias, o que pode ser mais difícil para alguns conteúdos ou áreas do conhecimento. Mais de $90 \%$ dos alunos aprovaram a indicação de videoaulas pelo professor, o que atesta que o esforço pode valer a pena.

\section{AGRADECIMENTOS}

Agradecemos à Fundação de Apoio à Pesquisa e Inovação do Estado de Santa Catarina (Fapesc) pelo financiamento, ao (Life) da (Furb), bem como à Furb e ao IFSC pelas condições oferecidas para a realização deste trabalho.

\section{REFERÊNCIAS}

ARANHA, Carolina Pereira et al. O YouTube como ferramenta educativa para o ensino de ciências. Olhares \& Trilhas, Uberlândia, v. 21, n. 1, p. 10-25, 2019. Disponível em: http://www.seer.ufu.br/index.php/olharesetrilhas/article/view/46164. Acesso em: 1으 maio 2020.

BARBA, Mariana Della. Pisa: Brasil aumenta investimento em educação mas continua no grupo dos "lanternas". BBC Brasil, 6 dez. 2016. Disponível em: http://www.bbc.com/portuguese/internacional-38205956. Acesso em: 29 abr. 2020.

BERGMANN, Jonathan; SAMS, Aaron. Sala de aula invertida: uma metodologia ativa de aprendizagem. Tradução Afonso Celso da Cunha Serra. 1. ed. Rio de Janeiro: LTC, 2016.

CARRAVETA, Luiza Maria Cesar. Do microensino à vídeo-aula na era digital. Revista Famecos, Porto Alegre, v. 22, n. 2, p. 48-65, 2015. Disponível em: http://dx.doi.org/10.15448/1980-3729.2015.2.21045. Acesso em: 29 abr. 2020.

DASH, Anil. Introducing The microcontent client. 2002. Disponível em: https://anildash.com/2002/11/13/ introducing-microcontent-client/. Acesso em: 29 abr. 2020.

DIAS, Ana Isabel de Azevedo Spinola; ESPOSITO JUNIOR, Antonio; DEMARQUE, Reginaldo. Incorporação de mídias eletrônicas na aprendizagem de matemática. In: COLÓQUIO DE HISTÓRIA E TECNOLOGIA NO ENSINO DE MATEMÁTICA, 6., 2013. São Carlos. Anais [...]. São Carlos: Ufscar, 2013. Disponível em: http:// www2.dm.ufscar.br/anais/artigoscompletos/artigocompleto_OC_T1_SS_AnalsabelSpinola-ReginaldoDemarque-AntonoEsposito.pdf. Acesso em: 21 jan. 2016.

EDUCAUSE. 7 Things you should know about flipped classrooms. 2012. Disponível em: https://library.educause.edu/-/media/files/library/2012/2/eli7081-pdf.pdf. Acesso em: 29 abr. 2020. 
FRANCISCO, Rodrigo Catafesta et al. Videoaulas como apoio ao processo de aprendizagem digital sobre o tratamento de esgoto sanitário. E-Tech: Tecnologias para competitividade industrial, Florianópolis, v. 8, n. 2, p. 71-84, 2015. Disponível em: http://etech.sc.senai.br/index.php/edicao01/article/view/850/416. Acesso em: 29 abr. 2020.

FRANCO, Maria Laura P. B. Análise de conteúdo. 3. ed. Brasília: Liber Livro Editora, 2008. 80 p.

HIRDES, João Carlos Roedel et al. Monitoria em vídeo: o uso das novas tecnologias de comunicação no processo de ensino-aprendizagem. In: ENCONTRO GAÚCHO DE EDUCAÇÃO MATEMÁTICA, 9., 2006, Caxias do Sul. Anais [...]. Caxias do Sul: UCS, 2006. p. 1-10. V. 1. Disponível em: http://miltonborba.org/CD/Interdisciplinaridade/Encontro_Gaucho_Ed_Matem/cientificos/CC56.pdf. Acesso em: 29 abr. 2020.

HUBERMAN, Michael. O ciclo de vida profissional dos professores. In: NÓVOA, António (org.). Vidas de professores. Porto: Porto Editora. 1992. p. 31-61.

KHAN, Salman. Um mundo, uma escola: a educação reinventada. Rio de Janeiro: Intrínseca, 2013. 255 p. KRIPKA, Rosana Maria Luvezute; VIALI, Lori; LAHM, Regis Alexandre. Tecnologias de informação e comunicação na formação de professores. Revista Eletrônica Debates em Educação Científica e Tecnológica, v. 6, n. 1, p. 45-57, 2016. ISSN: 2236-2150. Disponível em: https://ojs.ifes.edu.br/index.php/dect/article/ view/145. Acesso em: 29 abr. 2020.

LIMA, Leandro Holanda Fernandes de; MOURA, Flavia Ribeiro de. O professor no ensino híbrido. In: BA$\mathrm{CICH}$, Lilian; TANZI NETO, Adolfo; TREVISANI, Fernando de Mello (org.). Ensino híbrido: personalização e tecnologia na educação. Porto Alegre: Penso, 2015. p. 89-102.

LISBÔA, Eliana Santana; BOTTENTUIT JUNIOR, João Batista; COUTINHO, Clara Pereira. O contributo do vídeo na educação online. In: CONGRESSO INTERNACIONAL GALEGO-PORTUGUÊS DE PSICOPEDAGOGIA, 10., 2009. Braga. Actas [...]. Braga: Universidade do Minho, 2009. p. 5.858-5.868. Disponível em: http:// repositorium.sdum.uminho.pt/bitstream/1822/9593/1/ContributoVideo.pdf. Acesso em: 29 abr. 2020.

MARTINS, Shirley Mônica Silva; BARRETO, Betânia Maria Vilas Bôas; BORGES, Leônidas Leão. Audiovisual e educação: a videoaula e as novas implicações pedagógicas. In: CONGRESSO BRASILEIRO DE CIÊNCIAS DA COMUNICAÇÃO, 32., 2009. Curitiba. Anais [...]. Curitiba: Intercom, 2009. Disponível em: http://www. intercom.org.br/papers/nacionais/2009/resumos/R4-2165-1.pdf. Acesso em: 29 abr. 2020.

MEDINA, Camila Beltrão; BACELAR, Roberta Baldo. O uso do audiovisual como ferramenta de transmissão do conhecimento no ensino superior. Acervo On-line de Mídia Regional, Brasil, v. 11, n. 1, p. 89109, jan./jun. 2016. Disponível em: http://revistas.univerciencia.org/index.php/midiaregional/article/ view/9129/8101. Acesso em: 6 abr. 2016.

MORAN, José Manuel. Ensino e aprendizagem inovadores com tecnologias audiovisuais e telemáticas. In: MORAN, José Manuel; BEHRENS, Marilda Aparecida; MASETTO, Marcos T. Novas tecnologias e mediação pedagógica. 8. ed. Campinas: Papirus, 2004. p. 11-65.

MORAN, José Manuel. Interferências dos meios de comunicação no nosso conhecimento. Revista Brasileira de Comunicação, São Paulo, v. 7, p. 36-49, 1994. Disponível em: http://portcom.intercom.org.br/ revistas/index.php/revistaintercom/article/view/844/752. Acesso em: 29 ago. 2020.

MORAN, José Manuel. Vídeos são instrumentos de comunicação e de produção. 2009. Disponível em: http://portaldoprofessor.mec.gov.br/noticias.html?idEdicao=16\&idCategoria=8. Acesso em: 29 ago. 2020.

PAIVA, Thais. Brasil mantém últimas colocações no Pisa. Carta Educação. 6 dez 2016. Disponível em: http://www.cartaeducacao.com.br/reportagens/brasil-mantem-ultimascolocacoes-no-pisa/. Acesso em: 28 out. 2021.

PRENSKY, Marc. Digital natives, digital immigrants part 1. On the horizon, Estados Unidos: MCB University Press, v. 9, n. 5, p. 1-6, 2001. Disponível em: http://www.marcprensky.com/writing/Prensky\%20-\%20Digital\%20Natives,\%20Digital\%20lmmigrants\%20-\%20Part1.pdf. Acesso: 29 ago. 2020.

SANT'ANNA, Flávia. Microensino e habilidades técnicas do professor. São Paulo: McGraw-Hill do Brasil, 1979. $252 \mathrm{p}$.

SIBILIA, Paula. Redes ou paredes: a escola em tempos de dispersão. Rio de Janeiro: Contraponto, 2012.

SILVA, Luciano Dias da. A videoaula no Ensino Médio como recurso didático pedagógico no contexto da sala de aula invertida. 2017. 124 f. Dissertação (Mestrado Profissional em Ensino de Ciências Naturais e Matemática) - Universidade Regional de Blumenau, Centro de Ciências Naturais e Matemática, Blumenau, 2017a. Disponível em: http://www.bc.furb.br/docs/DS/2017/363210_1_1.pdf. Acesso em: 29 ago. 2020. 
SILVA, Luciano Dias da. As Videoaulas. Youtube, 20 jun. 2017b. Disponível em: https://www.youtube.com/ watch?v=ygOPU4f45LQ\&t=0s\&index=4\&list=PLJb-gl4WjTOnZBseMvL2Z6oSk-mlcMTur. Acesso em: 29 ago. 2020.

SILVA, Rodrigo Abrantes da; CAMARGO, Ailton Luiz. A cultura escolar na era digital: o impacto da aceleração tecnológica na relação professor-aluno, no currículo e na organização escolar. In: BAClCH, Lilian; TANZI NETO, Adolfo; TREVISANI, Fernando de Mello (org.). Ensino híbrido: personalização e tecnologia na educação. Porto Alegre: Penso, 2015. p. 169-190.

SILVEIRA, Sidnei Renato et al. Sala de aula invertida: desenvolvendo vídeo-aulas para a pré-aula. Redin Revista Educacional Interdisciplinar, v. 8, n. 1, 2019. Disponível em: http://seer.faccat.br/index.php/redin/ article/view/1537. Acesso em: 10 maio 2020.

TREVELIN, Ana Teresa Colenci; PEREIRA, Marco Antonio Alves; OLIVEIRA NETO, José Dutra de. A utilização da "sala de aula invertida" em cursos superiores de tecnologia: comparação entre o modelo tradicional e o modelo invertido "flipped classroom" adaptado aos estilos de aprendizagem. Revista de Estilos de Aprendizagem, v. 11, n. 12, p. 1-14, 2013. Disponível em: http://revistaestilosdeaprendizaje.com/article/ view/992. Acesso em: 29 ago. 2020.

VALENTE, José Armando. Blended learning e as mudanças no ensino superior: a proposta da sala de aula invertida. In: Educar em Revista, Curitiba: Editora UFPR, Edição Especial, $\mathrm{n}$. 4, p. 79-97, 2014. Disponível em: https://www.scielo.br/scielo.php?script=sci_abstract\&pid=S0104-40602014000800079\&Ing=en\&nrm=iso\&tlng=pt. Acesso em: 29 ago. 2020.

VEEN, Wim; VRAKKING, Ben. Homo zappiens: educando na era digital. Tradução Vinicius Figueira. Porto Alegre: Artmed, 2009. $139 \mathrm{p}$.

VIALLI, Alexandre et al. Gestão do enriquecimento da elaboração de videoaulas: uma proposta de aumento da interatividade entre professor e estudante. In: SIMPÓSIO DE EXCELÊNCIA EM GESTÃO E TECNOLOGIA, 8., 2011. Resende: AEDB, 2011. Disponível em: http://www.aedb.br/seget/arquivos/artigos11/33114413.pdf. Acesso em: 29 ago. 2020.

ZANATA, Eliana Marques; CARAMANO, Elana Simone Schiavo; MARQUES, Antonio Francisco. Tecnologias da informação e comunicação na educação de jovens e adultos. In: MAGNONI JÚNIOR, Lourenço et al. (org.). Programa Educativo e Social JC na Escola: luz, ciência e vida. 2. ed. São Paulo: Centro Paula Souza, 2016. p. 117-126. Disponível em: http://www.agbbauru.org.br/publicacoes/revista/LivroSNCT2016-2ed/ LivroSNCT2016-2ed-21.pdf. Acesso em: 29 ago. 2020. 